\title{
On the Impact of Trade in a Common Property
}

\section{Renewable Resource Oligopoly*}

\author{
Hassan Benchekroun ${ }^{\dagger}$ \\ McGill University and CIREQ
}

\author{
Amrita Ray Chaudhuri ${ }^{\ddagger}$ \\ The University of Winnipeg, CentER \& TILEC
}

Dina Tasneem ${ }^{\S}$

The American University of Sharjah 


\section{Introduction}

A significant and rising share of world trade consists of natural resources. ${ }^{1}$ This includes trade in renewable resources such as fish. For example, world exports of fish increased by 60 per cent from 33 million tonnes to 53 million tonnes between 1990 and 2007, according to statistics from the United Nations Food and Agriculture Organization (FAO). In value terms, world fish exports rose from $\$ 53$ billion in 1998 to $\$ 98$ billion in 2008 . In Canada, for instance, fisheries products are the largest single food commodity export. ${ }^{2}$ Trade in certain renewable resources is further facilitated by the structure of tariffs they face in export markets with tariff rates rising with the stage of processing. Policy analysis regarding trade in renewable resources is complicated by the fact that their extraction often generates negative externalities. In the case of fisheries, open access in the absence of well defined property rights may lead to over-exploitation and eventual depletion of the resource stock if each firm aims to maximize its individual profit without internalising the impact of its own extraction on rivals' extraction prospects. Thus, for common property resources, a dynamic analysis is warranted since current policies are inextricably linked with welfare of future generations. In this paper, we use a differential game to examine whether policies that promote free trade in such resources improve the welfare of trading partners.

Our model setup consists of $n$ countries with one firm each. All firms extract the renewable resource from a common pool. Each country also consumes the resource. Thus, under autarky, each country is served by a monopolist. Under free trade, the firms compete in quantities in a single integrated market. Our setting reflects the market structure in industries such as fish where a few large fishing companies behave oligopolistically in the global market. ${ }^{3}$ The firms use closed loop strategies such that, at any instant in time, each firm's

\footnotetext{
${ }^{1}$ While the volume has remained fairly stable during the last decades, representing about 24 per cent of world merchandise trade in 2008 according to the World Trade Organization (WTO), in value terms trade in natural resources has grown annually at around 20 per cent. See the World Trade Report 2010 for further details: https://www.wto.org/english/res e/booksp e/anrep e/wtr10-2a e.pdf

${ }^{2}$ See Fisheries and Oceans Canada for further details: http://www.dfo-mpo.gc.ca/stats/trade-commeng.htm

${ }^{3}$ We note that a number of papers have studied trade of renewable resources in a perfectly competitive
} 
extraction is a function of the resource stock, which in turn depends on the extraction of all firms. The advantage of using closed loop strategies is that they yield subgame perfect Nash equilibria, while open loop strategies, where extraction is a function of time but not the stock, typically do not. ${ }^{4}$

We note that a number of papers in the previous literature have used a differential game framework with closed loop strategies to analyze common property resources, although they analyze a closed economy context rather than allowing for trade across countries. For example, Benchekroun (2003) examines the impact of unilateral production restrictions, while Benchekroun (2008) examines the effect of changes in the natural growth rate of the stock and of the number of firms. These papers, together with Lambertini and Mantovani $(2014,2016)$ characterize the subgame perfect Nash equilibria of a common property duopoly, highlighting different features. They show that extraction strategies and value functions take a piecewise-linear form, which depends on the resource stock level. There can be a unique or multiple long-run stationary equilibria, depending on the parameters of the model. Also, nonlinear feedback solutions may be unstable. Fujiwara (2008) builds on Benchekroun (2003) to show that linear feedback strategies lead to a smaller output than monopoly, static duopoly and non-linear feedback strategies. Taking into account such strategic behaviour and possible non-linearities of the growth of the resource stock, Colombo and Labrecciosa (2013a, 2013b) examine the role of property rights and convergence to the Cournot equilibrium, while others characterize the optimal taxation policy (see, for example, Kossioris et al., 2011). Within a similar setting, while Fujiwara (2011) examines losses from competition, Benchekroun and Gaudet (2015) study the impact of mergers. Benchekroun and Long (2016) introduce a concept of firms' social status which depends either on extraction levels or profit levels, while Grilli and Bisceglia (2017) consider a finite planning horizon. Vardar and Zaccour (2018) extend Benchekroun (2008) by introducing pollution externalities that are generated

market using the logistic function to represent biological growth of the resource in a constrained environment (see, for example, Munro, 1979; Brander and Taylor, 1997, 1998; Hannesson, 2000; Jinji, 2006, 2007).

${ }^{4}$ See Batabyal and Beladi (2006) for an analysis using open loop strategies with a single buyer and competitive sellers. 
as a by-product of extraction. We contribute to this literature by comparing the equilibria under autarky and free trade within a setting similar to that used in the above papers. ${ }^{5}$

Our work is more closely related to Fujiwara and Shinozaki (2010) which examines the effect of trade liberalization in a common property duopoly. They find that although the effect of reductions in trade costs on welfare is non-monotonic, welfare under autarky is unambiguously higher than that under free trade, a result that is in contrast to that derived in static models and driven by the feedback strategies used by firms. Our model setting differs from Fujiwara and Shinozaki (2010) in the following ways. We assume that under free trade, there exists a single integrated market rather than markets that are segmented across countries. We include $n>2$ firms in our oligopoly. Moreover, while Fujiwara and Shinozaki (2010) focus solely on the steady state welfare level, we also analyze the effect of moving from autarky to free trade on the transition to the steady state.

Our first contribution is to show that, within our context, the steady state stock level is unambiguously lower under free trade than under autarky, implying that the externalities due to open access are exacerbated by allowing for trade. This is in line with empirical observations. While world exports of fish increased by 60 per cent between 1990 and 2007, world fisheries production rose by 42 per cent from 98 million tonnes to 140 million tonnes, according to FAO. However, annual catches from oceans and fresh water fisheries were constant during this period, at around 90 million tonnes, with most of the growth in production and trade accounted for by aquaculture. These statistics have raised concerns that the world's oceans and fresh water fisheries may have reached peak production and could be over-exploitated in the face of growing demand, as summarised by the World Trade Report 2010. This may also explain why renewable resources are twice as likely to face export taxes as other sectors, as noted in the WTO's Trade Policy Reviews. ${ }^{6}$

\footnotetext{
${ }^{5} \mathrm{~A}$ few papers also study different aspects of trade in renewable resources that we abstract away from in this paper. For example, one stream of the literature endogenizes the role of institutions (see Bulte and Barbier, 2005, for a survey). Quaas and Stöven (2014) apply new trade theory with consumers' love for variety to the case of renewable resources.

${ }^{6}$ Around 11 per cent of world trade in natural resources is covered by export taxes, while just 5 per cent of world trade is covered by export taxes. Moreover, 15 to 25 per cent of world trade in fish is estimated to
} 
The impact of trade on consumer surplus of an individual country is a priori ambiguous. On the one hand, the smaller resource stock in the long run leads to lower consumption (and consumer surplus) in the long run. At the same time, higher extraction in the short run leads to higher consumption (and consumer surplus) in the short run. A natural question that arises, and which has not been addressed in the previous literature, is whether consumers are better off due to freer trade once we aggregate their gains and losses over time. By capturing the transition dynamics, we are able to show that aggregate consumer surplus over time decreases due to freer trade as long as the stock does not exceed a certain threshold, in sharp contrast to most static trade models. ${ }^{7}$ Producer surplus always decreases with a move from Autarky to Free Trade. Together, the results on consumer and producer surplus imply that there exists a threshold in terms of the stock level below which aggregate social welfare over time is lower under Free Trade than under Autarky.

The paper is organized as follows. Section 2 presents the benchmark case of autarky. Section 3 presents the free trade scenario. Section 4 compares autarky and free trade. All variables representing the Autarky scenario are denoted by the superscript " $A$ ", while all variables respresenting the Free Trade scenario are denoted by the superscript "FT". Section 5 presents our concluding remarks.

\section{The Benchmark Model: Autarky}

We consider a renewable resource that is harvested by $n$ countries. There exists one firm in each country, which is a monopoly in the supply of the renewable resource in its domestic market in the absence of trade. We assume that the countries are exploiting a common pool for consumption in the domestic markets. The stock of the renewable resource is denoted be covered by export taxes, relative to 5 to 10 per cent of world trade in fuels and mining.

${ }^{7}$ Another paper to focus on aggregate consumer surplus over time for a common pool renewable resource sector, using a closed-loop differential game model, is Colombo and Labrecciosa (2018). They examine the impact of increased cooperation between firms, rather than that of freer trade. They show that increased cooperation makes consumers worse off in the short run and better off in the long run such that the discounted sum of consumer surplus increases in cooperation for initial stock levels below a threshold. 
by $S$. The natural reproduction function of the stock is given by $F(S)$ with

$$
F(S) \equiv\left\{\begin{array}{lll}
\delta S & \text { for } \quad S \leq S_{y} \\
\delta S_{y}\left(\frac{\bar{S}-S}{\bar{S}-S_{y}}\right) & \text { for } \quad S>S_{y}
\end{array}\right.
$$

and

$$
S(0)=S_{0}
$$

where $\delta>0$ represents the intrinsic growth rate of the resource. When the stock exceeds a threshold stock $S_{y}$ the rate of growth of the resource diminishes with the stock. Thus $\delta S_{y}$ represents the maximum sustainable yield (MSY). $\bar{S}$ represents the carrying capacity of the habitat. That is, for a stock level beyond $\bar{S}>S_{y}$ growth is limited by the habitat and is negative. For simplicity, we normalize $\bar{S}$ to 1 .

Each firm simultaneously extracts the available resource to maximize the present value of its discounted payoff over an infinite horizon. Let the extraction rate of each firm $i \in$ $(1,2, \ldots, n)$ at time $t$ be denoted by $q_{i}(t)$. Each firm faces a linear inverse demand function given by $P_{i}^{A}=a-b q_{i}^{A}$ with $i=1,2, \ldots n$, and zero marginal cost of extraction. Therefore, firm $i^{\prime} s$ instantaneous payoff at time $t$ is given by:

$$
\pi_{i}^{A}\left(q_{i}^{A}(t)\right)=\left[a-b q_{i}^{A}(t)\right] q_{i}^{A}(t)
$$

For each firm, and thereby each country, the instantaneous payoff is maximized when $q^{A}=\frac{a}{2 b}$.

Assuming that the stock can be observed by each firm and used for conditioning behavior, we focus on the set of stationary Markovian strategies, as given by:

$$
q_{i}^{A}(t)=\phi_{i}^{A}(S(t))
$$

Thus, at any point in time, the extraction decision of a country depends only on the level of the stock at that moment. 
Firm $i$ takes the other firms' strategies as given and chooses a stationary Markovian strategy that maximizes the following:

$$
\begin{aligned}
J_{i}^{A} & =\int_{0}^{\infty} \pi_{i}^{A}\left(q_{i}^{A}(t)\right) e^{-r t} d t \\
\text { s.t. } & \\
S(t) & =F(S(t))-\Sigma_{j=1}^{n} q_{j}^{A}(S(t)) \\
S(0) & =S_{0} \\
q_{i}^{A}(t) & \geq 0,
\end{aligned}
$$

where $r>0$ is the common discount rate.

Assumption 1: We assume that $\delta>\delta_{0}$, where

$$
\delta_{0} \equiv \frac{r\left(1+n^{2}\right)}{2}
$$

Assumption 1 ensures that the rate of growth of the stock is sufficiently large relative to the rate of discount, $r$, such that an interior positive stable steady state stock exists under free trade (see Benchekroun, 2008).

Assumption 2: We assume that

$$
S_{y} \geq S_{2}^{A} \equiv \frac{a n}{2 \delta b}
$$

Assumption 2 ensures that it is possible to sustain a consumption rate that maximizes each agent's instantaneous utility. It also ensures that a positive steady state exists under Autarky.

Given the autonomous nature of each firm's problem, we focus on stationary Markovian strategies and use a dynamic programming approach to characterize the feedback equilibrium of this differential game (see Dockner et al., 2000, Ch 4.). Let $\left(\phi_{1}^{A *}, . ., \phi_{n}^{A *}\right)$ be a subgame 
perfect Markov Nash equilibrium. Let $V_{i}^{A}(S)$ be firm $i^{\prime} s$ value function such that $V_{i}^{A}(S)=$ $\int_{0}^{\infty} \pi_{i}^{A}\left(\phi_{i}^{A *}\left(S^{*}(t)\right)\right) e^{-r t} d t$ with $S(0)=S$. The Hamilton-Jacobi-Bellman equation associated with firm $i$ 's problem is given by:

$$
r V_{i}^{A}(S)=\max _{\phi_{i}^{A}}\left[\phi_{i}^{A}\left(a-b \phi_{i}^{A}\right)+V_{i}^{A \prime}\left(F(S)-\phi_{i}^{A}-(n-1) \phi^{A *}\right)\right] .
$$

Proposition 1 Let

$$
\phi^{A *}(S) \equiv \begin{cases}0 & \text { for } 0 \leq S<S_{1}^{A} \\ w^{A}+z^{A} S & \text { for } S_{1}^{A} \leq S \leq S_{2}^{A} \\ \frac{a}{2 b} & \text { for } S>S_{2}^{A}\end{cases}
$$

where

$$
w^{A} \equiv-\frac{a}{2 b \delta} \frac{\delta-n r}{2 n-1}, z^{A} \equiv \frac{2 \delta-r}{2 n-1}
$$

and

$$
S_{1}^{A} \equiv \frac{a(\delta-n r)}{2 b \delta(2 \delta-r)}
$$

The vector $\left(\phi^{A *}, . ., \phi^{A *}\right)$ constitutes a symmetric Markov-perfect Nash equilibrium (MPNE) of the Autarky game.

Proof: See Appendix.

The extraction strategy under Autarky, as presented by (4), is depicted in Figure 1. 


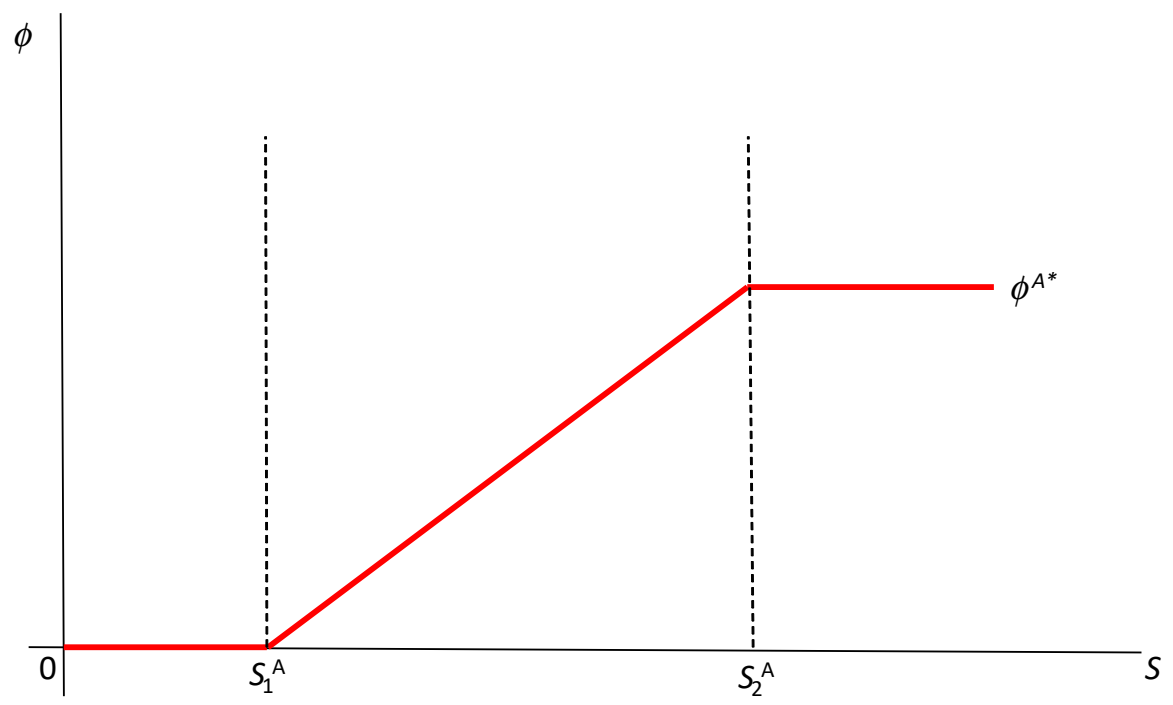

Figure 1: Extraction strategy under Autarky

Remark 1: Under the MPNE of the Autarky game, there are two positive steady state resource stocks that are given by:

$$
S_{1, \infty}^{A}=S_{2}^{A} \text { and } S_{2, \infty}^{A}=\frac{a n\left(S_{y}-1\right)}{2 b \delta S_{y}}+1>S_{1, \infty}^{A}
$$

with $S_{1, \infty}^{A}$ semi-stable with basin of attraction $\left(0, S_{2}^{A}\right]$, and $S_{2, \infty}^{A}$ locally asymptotically stable with basin of attraction $\left(S_{2}^{A}, \infty\right)$. Note that for $S \in\left(S_{2}^{A}, \infty\right)$ the outcome of the MPNE $\left(\phi^{A *}, . ., \phi^{A *}\right)$ corresponds to the outcome of a repeated static game where the resource is abundant. To sum up, the MPNE results in the following steady states under Autarky:

$$
\lim _{t \rightarrow \infty} S^{A *}(t)= \begin{cases}S_{1, \infty}^{A} & S_{0} \leq S_{2}^{A} \\ S_{2, \infty}^{A} & S_{0}>S_{2}^{A}\end{cases}
$$

\section{Free Trade}

This section extends the benchmark model, as presented in the previous section, to allow for free trade among the $n$ countries. We assume that the firms behave as oligopolists, and supply their harvest to an integrated market which consists of all the $n$ countries' domestic 
markets. Let $q_{i}^{F T}(t)$ denote the quantity harvested and supplied by firm $i$ at time $t$. The inverse market demand function $P^{F T}(q)$ is given by $P^{F T}=a-\frac{b}{n} q$, where $q=\sum_{j=1}^{n} q_{j}^{F T}$.

The instantaneous payoff function of firm $i$ is given by:

$$
\pi_{i}^{F T}\left(q_{1}^{F T}(t), q_{2}^{F T}(t), \ldots, q_{n}^{F T}(t)\right)=q_{i}^{F T}(t)\left(a-\frac{b}{n} \sum_{j=1}^{n} q_{j}^{F T}(t)\right)
$$

Firm $i$ takes the other firms' strategies as given and chooses a stationary Markovian strategy that maximizes the following:

$$
\begin{aligned}
J_{i}^{F T} & =\int_{0}^{\infty} \pi_{i}^{F T}\left(q_{1}^{F T}(t), q_{2}^{F T}(t), \ldots, q_{n}^{F T}(t)\right) e^{-r t} d t \\
\text { s.t. } & \\
\dot{S(t)} & =F(S(t))-\sum_{j=1}^{n} q_{j}^{F T}(S(t)) \\
S(0) & =S_{0} \\
q_{i}^{F T}(t) & \geq 0,
\end{aligned}
$$

Assumptions 1 and 2 continue to hold.

The Hamilton-Jacobi-Bellman equation associated with the problem of firm $i$ is given by:

$$
r V_{i}^{F T}(S)=\max _{\phi_{i}^{F T}}\left[\phi_{i}^{F T}\left(a-\frac{b}{n}\left(\phi_{i}^{F T}+(n-1) \phi^{F T *}\right)\right)+V_{i}^{F T \prime}\left(F(S)-\phi_{i}^{F T}-(n-1) \phi^{F T *}\right)\right] .
$$

\section{Proposition 2 Let}

$$
\phi^{F T *}(S) \equiv \begin{cases}0 & 0 \leq S \leq S_{1}^{F T} \\ w^{F T}+z^{F T} S & S_{1}^{F T}<S \leq S_{2}^{F T} \\ \frac{a n}{b n+b} & S>S_{2}^{F T}\end{cases}
$$


where

$$
w^{F T} \equiv-\frac{a\left(2 \delta-\left(n^{2}+1\right) r\right)}{2 b \delta n(n+1)}, z^{F T} \equiv \frac{(n+1)(2 \delta-r)}{2 n^{2}}
$$

and

$$
S_{1}^{F T} \equiv \frac{a n\left(2 \delta-r\left(1+n^{2}\right)\right)}{b \delta(n+1)^{2}(2 \delta-r)} \text { and } S_{2}^{F T} \equiv \frac{a n\left(n^{2}+1\right)}{b \delta(n+1)^{2}} \text {. }
$$

The vector $\left(\phi^{F T *}, . ., \phi^{F T *}\right)$ constitutes a symmetric Markov-perfect Nash equilibrium (MPNE) of the Free Trade game.

Proof: See Appendix.

The extraction strategy under Free Trade, as presented by (8), is depicted in Figure 2.

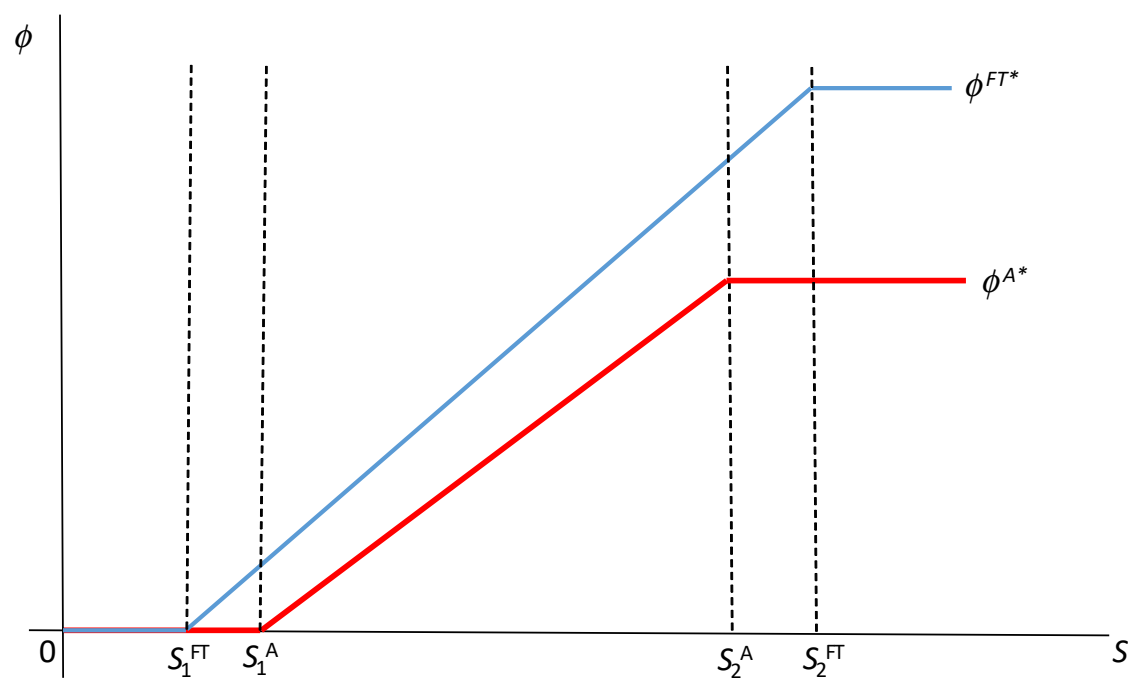

Figure 2: Extraction strategies under Autarky and Free Trade

Remark 2: Under the MPNE $\left(\phi^{F T *}, . ., \phi^{F T *}\right)$ of the free trade game there is either one positive steady state (when $S_{y} \leq \frac{a n^{2}}{\delta b(1+n)}$ ) with stock level denoted by $S_{1, \infty}^{F T}$, or three positive steady states (when $S_{y}>\frac{a n^{2}}{\delta b(1+n)}$ ) with stock levels denoted by $S_{1, \infty}^{F T}, S_{2, \infty}^{F T}$ and $S_{3, \infty}^{F T}$ with

$$
\begin{gathered}
S_{1, \infty}^{F T} \equiv-\frac{a n\left(-2 \delta+n^{2} r+r\right)}{b \delta(n+1)(2 \delta-(n+1) r)}, \\
S_{2, \infty}^{F T} \equiv \frac{a n^{2}}{b \delta n+b \delta}
\end{gathered}
$$


and

$$
S_{3, \infty}^{F T} \equiv \frac{a n^{2}\left(S_{y}-1\right)}{b \delta(n+1) S_{y}}+1
$$

Moreover, it is straightforward to show that $S_{1, \infty}^{F T}$ is locally asymptotically stable with basin of attraction $\left(0, S_{2, \infty}^{F T}\right)$ whereas $S_{2, \infty}^{F T}$ is unstable and $S_{3, \infty}^{F T}$ is locally asymptotically stable with basin of attraction $\left(S_{2, \infty}^{F T}, \infty\right)$. Note that for $S \in\left(S_{2, \infty}^{F T}, \infty\right)$, the outcome of the MPNE $\left(\phi^{F T *}, . ., \phi^{F T *}\right)$ corresponds to the outcome of a repeated static game where the resource is abundant.

\section{Autarky vesus Free Trade}

This section provides a comparison of the scenarios with and without trade. We begin by comparing the harvesting strategies under Autarky and Free Trade, as given by (4) and (8) respectively.

Proposition 3 In the short-run, a move from Autarky to Free Trade results in an increase in extraction for all resource stock levels above $S_{1}^{F T}$.

Proof: It follows from (5) and (9) that

$$
\frac{S_{1}^{A}}{S_{1}^{F T}}>1 .^{8}
$$

From (13), we have that, when $S \leq S_{1}^{F T}$, extraction under Autarky and Free Trade are both nil. From (2) and (9), it follows that:

$$
\frac{S_{2}^{A}}{S_{2}^{F T}}<1 \text { for all } n \geq 2 .^{9}
$$

${ }^{8}$ We have $\frac{S_{1}^{A}}{S_{1}^{F T}}=\frac{(n+1)^{2}(\delta-n r)}{2 n\left(2 \delta-r\left(1+n^{2}\right)\right)}$, with

$$
(n+1)^{2}(\delta-n r)-2 n\left(2 \delta-r\left(1+n^{2}\right)\right)=(\delta+n r)(n-1)^{2}>0
$$

${ }^{9}$ We have $\frac{S_{2}^{A}}{S_{2}^{F T}}=\frac{1}{2} \frac{(n+1)^{2}}{n^{2}+1}<1$ for all $n \geq 2$. 
Moreover, comparing the slopes of the extraction strategies, we have that

$$
\frac{z^{A}}{z^{F T}}<1 \text { for all } n \geq 2 .{ }^{10}
$$

Together, (13), (14) and (15) imply the following:

$$
\phi^{A}(S) \leq \phi^{F T}(S) \text { for all } S \geq 0
$$

with

$$
\phi^{A}(S)<\phi^{F T}(S) \text { for all } S>S_{1}^{F T}
$$

Proposition 3 implies that the extraction level increases in the short run due to a move from Autarky to Free Trade, which has further implications for the long run, as discussed below.

\subsection{Steady State Resource Stock under Autarky and Free Trade}

Let

$$
\begin{gathered}
\Phi^{A *}(S) \equiv \sum_{i=1}^{n} \phi_{i}^{A *}(S), \\
\Phi^{F T *}(S) \equiv \sum_{i=1}^{n} \phi_{i}^{F T *}(S),
\end{gathered}
$$

let $S^{A *}(t)$ denote the equilibrium time path of the resource stock under Autarky, and let $S^{F T *}(t)$ denote the equilibrium time path of the resource stock under Free Trade.

Figures 3 and 4 below give the plots of $\Phi^{A *}(S), \Phi^{F T *}(S)$ and $F(S)$, when $S_{y}>\frac{a n^{2}}{\delta b(1+n)}$ and when $S_{y}<\frac{a n^{2}}{\delta b(1+n)}$, respectively.

\footnotetext{
${ }^{10}$ We have $\frac{z^{A}}{z^{F T}}=\frac{2 n^{2}}{2 n^{2}+n-1}<1$ for all $n \geq 2$.
} 


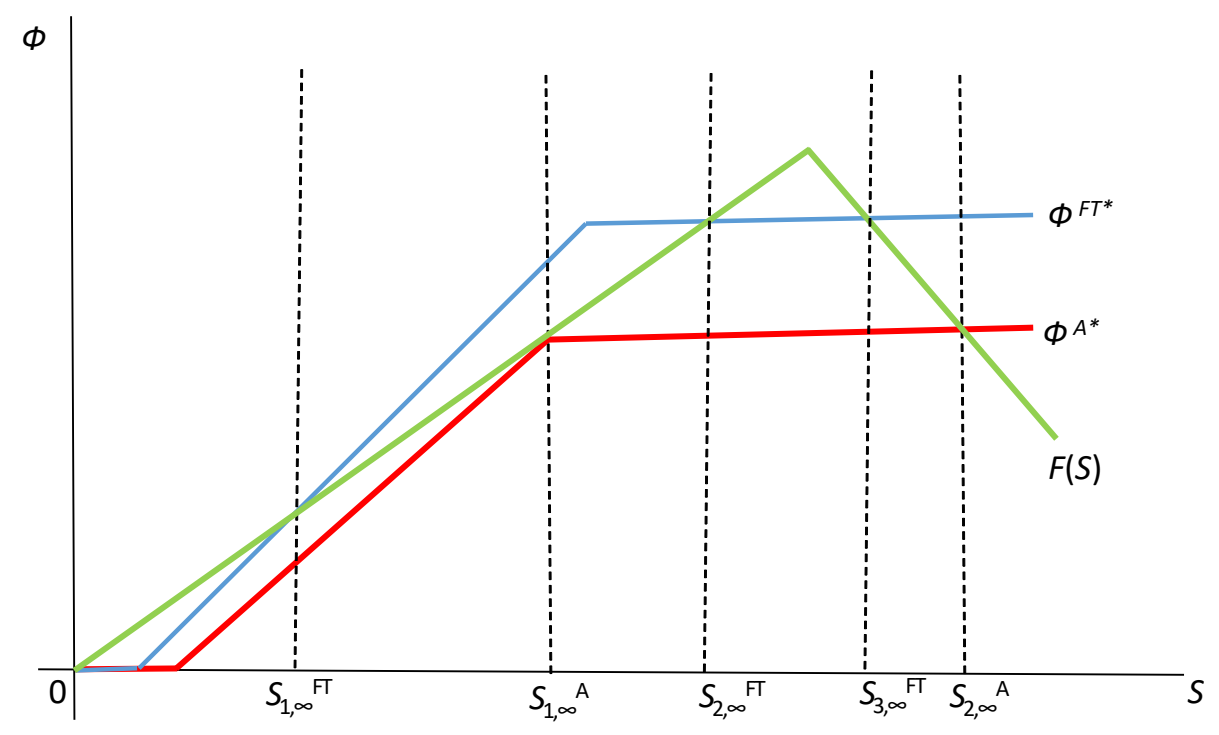

Figure 3: Total extraction when $S_{y}>\frac{a n^{2}}{\delta b(1+n)}$

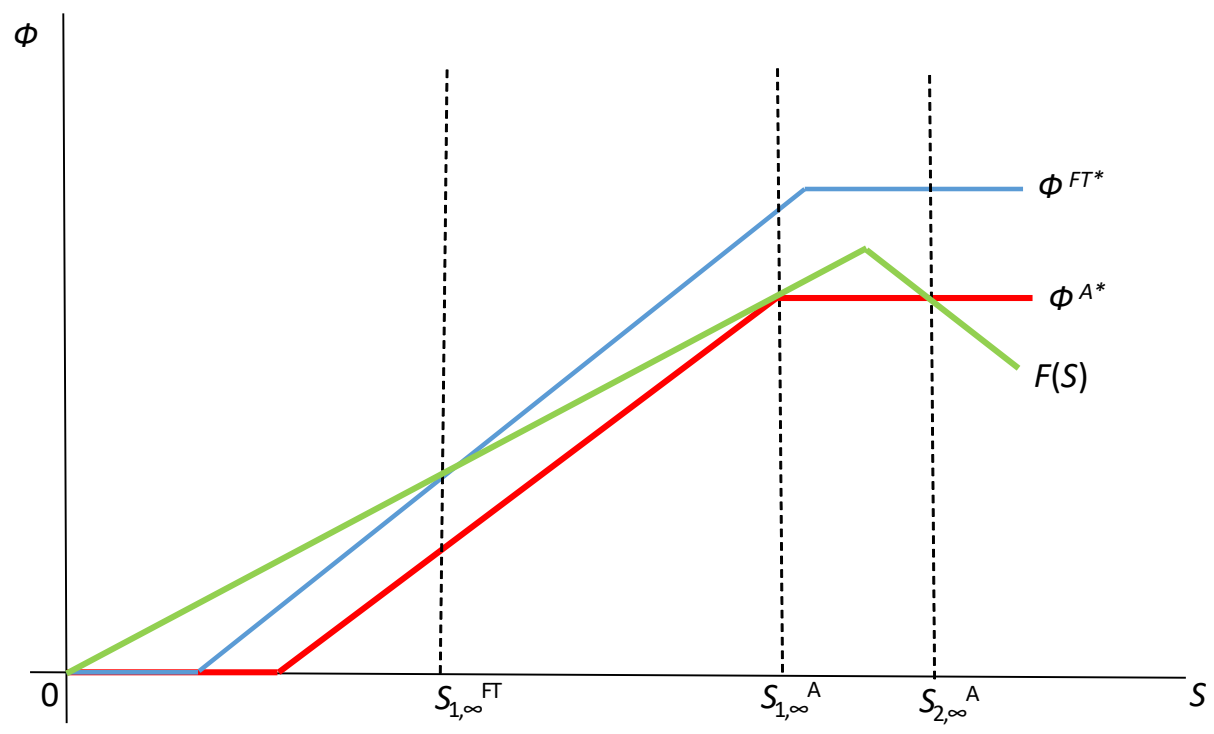

Figure 4: Total extraction when $S_{y}<\frac{a n^{2}}{\delta b(1+n)}$

It can be shown that the following holds:

$$
S_{1, \infty}^{F T}<S_{1, \infty}^{A}<S_{2, \infty}^{A}
$$

Moreover, for $S_{y}>\frac{a n^{2}}{\delta b(1+n)}$, it can be shown that the following holds:

$$
S_{1, \infty}^{F T}<S_{1, \infty}^{A}<S_{2, \infty}^{F T}<S_{3, \infty}^{F T}<S_{2, \infty}^{A}
$$


When $S_{y}>\frac{a n^{2}}{\delta b(1+n)}$, we split the state space into three regions: Region 1 corresponds to $S \in$ $\left(0, S_{2}^{A}\right]$, Region 2 corresponds to $S \in\left(S_{2}^{A}, S_{3, \infty}^{F T}\right)$ and Region 3 corresponds to $S \in\left[S_{3, \infty}^{F T}, \infty\right)$.

Proposition 4 Suppose $S_{y}>\frac{a n^{2}}{\delta b(1+n)}$.

For $S$ in Region 1, the steady state under Autarky and Free Trade are respectively $S_{1, \infty}^{A}$ and $S_{1, \infty}^{F T}$, with $S_{1, \infty}^{F T}<S_{1, \infty}^{A}$.

For $S$ in Region 2, there is no steady state under Autarky and an unstable steady state under Free Trade given by $S_{2, \infty}^{F T}$.

For $S$ in Region 3, the steady state under Autarky and Free Trade are respectively $S_{2, \infty}^{A}$ and $S_{3, \infty}^{F T}$, with $S_{3, \infty}^{F T}<S_{2, \infty}^{A}$.

Proof: See Appendix.

In Region 3, the outcomes of the Autarky and the Free Trade games correspond to the outcomes of a repeated static game where there is no resource constraint. Thus, in Region 3, the standard results of the impact of trade established in a static framework prevail.

When $S_{y}<\frac{a n^{2}}{\delta b(1+n)}$, the state space can be split into two regions: Region A corresponds to $\left.S \in 0, S_{1, \infty}^{A}\right]$ and Region B corresponds to $S \in\left(S_{1, \infty}^{A}, \infty\right)$.

Proposition 5 Suppose $S_{y}<\frac{a n^{2}}{\delta b(1+n)}$.

For $S$ in Region A, the steady state under Autarky and Free Trade are respectively $S_{1, \infty}^{A}$ and $S_{1, \infty}^{F T}$, with $S_{1, \infty}^{F T}<S_{1, \infty}^{A}$

For $S$ in Region B, the steady state under Autarky is given by $S_{2, \infty}^{A}$, and there is no steady state under Free Trade.

Again, in Region B, the resource is extracted as if there is no resource constraint. This is sustainable indefinitely under Autarky. However, under free trade the stock eventually enters Region A, and in the long-run the stock converges to the smallest positive steady state level, $S_{1, \infty}^{F T}$. Therefore, while in the short-run free trade results in an increase in consumption, the impact of free trade is to decrease consumption at the steady state. The impact of free trade 
on the discounted sum of consumer surplus is thus a priori undetermined. We examine this impact in the following section.

\subsection{Aggregate consumer surplus under Autarky and Free Trade}

From the analysis above, we can unambiguously state that when $S_{y}>\frac{a n^{2}}{\delta b(1+n)}$ for $S$ in Region 3, i.e., $S>S_{3, \infty}^{F T}$ the impact of free trade on consumer surplus, producer surplus and welfare is the same as in a repeated static game with no resource constraint. In this simple static game, it is straightforward to establish that the consumer (producer, welfare) surplus under free trade is larger (smaller, larger) than under autarky. Much less obvious is the impact of free trade on the aggregate consumer surplus and aggregate producer surplus in the case where the resource constraint is binding, i.e., $S<S_{3, \infty}^{F T}$.

While in the short-run consumer surplus under free trade is larger than under autarky, the opposite holds in the long-run. Aggregate consumer surplus of country $i$ consists of the discounted sum of instantaneous consumer surplus over the infinite horizon, and is given by:

$$
C S_{i} \equiv \int_{0}^{\infty} \frac{b}{2}(q(S(t)))^{2} e^{-r t} d t,{ }^{11}
$$

where $S(t)$ solves

$$
\begin{aligned}
\dot{S} & =F(S)-n q(S) \\
S(0) & =S_{0}
\end{aligned}
$$

Let $C S_{i}^{A}$ denote the aggregate consumer surplus of country $i$ under Autarky and $C S_{i}^{F T}$ denote the aggregate consumer surplus of country $i$ under Free Trade.

This can be computed for Autarky and for Free Trade using the respective extraction strategies. Alternatively, it can be shown that, when all firms adopt an extraction strategy

\footnotetext{
${ }^{11}$ Since there is one firm in each country, in the symmetric equilibrium, consumption in a country is equal to production of a single firm even under free trade. Thus, consumer surplus is a function of a single firm's output.
} 
$q(S)$, the feedback form of $C S$ satisfies the following differential equation:

$$
r C S_{i}=\frac{b}{2}(q(S))^{2}+C S_{i}^{\prime}(S)(F(S)-n q(S))
$$

When $q(S)$ is affine with $q(S)=w+z S$ the function $C S(S)$ is given by $C S(S)=A S^{2}+$ $B S+G$ where

$$
\begin{gathered}
A \equiv b \frac{z^{2}}{2 r-4 \delta+4 n z} \\
B \equiv \frac{-2 b w z \delta+b n w z^{2}+b r w z}{-3 r \delta+2 \delta^{2}+2 n^{2} z^{2}+r^{2}-4 n z \delta+3 n r z} \\
G \equiv \frac{2 b w^{2} \delta^{2}+b r^{2} w^{2}-3 b r w^{2} \delta+b n r w^{2} z}{4 r \delta^{2}-6 r^{2} \delta+2 r^{3}+6 n r^{2} z+4 n^{2} r z^{2}-8 n r z \delta}
\end{gathered}
$$

We can thus compute consumers surplus under autarky and under free trade for $S \in\left[S_{1}^{A}, S_{2}^{A}\right]$ by substituting $(w, z)$ respectively by $\left(w^{A}, z^{A}\right)$ and by $\left(w^{F T}, z^{F T}\right)$.

When $n=2$ we can show analytically that for $S \in\left[S_{1}^{A}, S_{2}^{A}\right]$ we have $C S^{A}(S)>$ $C S^{F T}(S)$ : while free trade always results in an increase (a decrease) in instantaneous consumer surplus in the short-run (long-run), the overall impact of free trade on consumer surplus when the transition dynamics is taken into account is to decrease aggregate consumer surplus. Numerical simulations for $n>2$ yield the same conclusion.

To prove our claim we write, for $n=2$,

$$
C S^{A}(S)-C S^{F T}(S)=h(\delta, r) S^{2}+k(\delta, r) S+l(\delta, r)
$$

with

$$
\begin{gathered}
h(\delta, r) \equiv-\frac{b\left(15 r^{4} \delta^{2}+15 r^{3} \delta^{3}-60 r^{2} \delta^{4}-60 r \delta^{5}\right)}{576 r \delta^{2}\left(r^{2}+3 r \delta+2 \delta^{2}\right)} \\
k(\delta, r) \equiv \frac{a}{576 r \delta^{2}\left(r^{2}+3 r \delta+2 \delta^{2}\right)}\left(12 r^{4} \delta+156 r^{3} \delta^{2}-480 r^{2} \delta^{3}+240 r \delta^{4}\right)
\end{gathered}
$$




$$
l(\delta, r) \equiv \frac{a^{2}}{576 r \delta^{2} b\left(r^{2}+3 r \delta+2 \delta^{2}\right)}\left(4 r^{4}-188 r^{3} \delta+312 r^{2} \delta^{2}-280 r \delta^{3}+80 \delta^{4}\right)
$$

Note that

$$
\begin{gathered}
h(\delta, r)=r h\left(\frac{\delta}{r}, 1\right) \\
k(\delta, r)=k\left(\frac{\delta}{r}, 1\right) \\
l(\delta, r)=\frac{1}{r} l\left(\frac{\delta}{r}, 1\right)
\end{gathered}
$$

and therefore the sign of $h, k, l$ depends on the ratio $\frac{\delta}{r}$ only, and that we can normalize $r$ to 1 for the rest of proof without loss of generality. This yields

$$
\begin{gathered}
h(\delta, 1)=\frac{5 b}{192}(2 \delta-1) \\
k(\delta, 1)=\frac{a}{48}(2 \delta-1) \frac{-15 \delta+10 \delta^{2}-1}{\delta(\delta+1)(2 \delta+1)} \\
l(\delta, 1)=\frac{a^{2}}{144 b} \frac{-47 \delta+78 \delta^{2}-70 \delta^{3}+20 \delta^{4}+1}{\delta^{2}(\delta+1)(2 \delta+1)}
\end{gathered}
$$

From Assumption 1 we have $\delta>\frac{5}{2}$ (recall that $n=2$ ) and therefore $h(\delta, 1)>0$.

The sign of $k(\delta, 1)$ is given by the sign of the following expression:

$$
-15 \delta+10 \delta^{2}-1=10\left(\delta-\left(\frac{1}{20} \sqrt{265}+\frac{3}{4}\right)\right)\left(\delta-\left(\frac{3}{4}-\frac{1}{20} \sqrt{265}\right)\right),
$$

which is a strictly convex quadratic function of $\delta$ with two real roots of opposite signs, $\left(\frac{3}{4}-\frac{1}{20} \sqrt{265}\right)$ and $\left(\frac{1}{20} \sqrt{265}+\frac{3}{4}\right)=1.5639$. Therefore, for all $\delta>\frac{5}{2}>1.5639$ we have $k(\delta, 1)>0$.

To establish that $l(\delta, 1)>0$ for $\delta>\frac{5}{2}$, we note that $l(\delta, 1)$ has the same sign as $\lambda(\delta) \equiv-47 \delta+78 \delta^{2}-70 \delta^{3}+20 \delta^{4}+1$. Since $\lambda^{\prime \prime}(\delta)=12\left(-35 \delta+20 \delta^{2}+13\right)>0$ for $\delta>\frac{5}{2}$, 
we have $\lambda^{\prime}(\delta)>\lambda^{\prime}\left(\frac{5}{2}\right)=\frac{561}{2}>0$ for all $\delta>\frac{5}{2}$ and, therefore, $\lambda(\delta)>\lambda\left(\frac{5}{2}\right)=\frac{117}{2}>0$ for $\delta>\frac{5}{2}$

This completes the proof that $l(\delta, 1)>0$ and, therefore, $h(\delta, r), k(\delta, r), l(\delta, r)>0$, implying that $C S^{A}(S)-C S^{F T}(S)>0$ for all $S \in\left[S_{1}^{A}, S_{2}^{A}\right]$.

We have, thus, proven that in Region $1, C S^{A}(S)>C S^{F T}(S)$ and, therefore, Free Trade results in a smaller aggregate consumer surplus than Autarky. This result, combined with the observation that in Region 3 we have $C S^{A}(S)<C S^{F T}(S)$, and using continuity of $C S(S)$, allows us to conclude that there exists a threshold stock $\tilde{S}$ in Region 2 such that $C S^{A}(\tilde{S})=C S^{F T}(\tilde{S})$ and $C S^{A}(S)<(>) C S^{F T}(S)$ for $S>(<) \tilde{S}$.

\subsection{Aggregate producer surplus under Autarky and Free Trade}

Next, we compare the producer surplus of each firm under Autarky and Free trade. Since we have a symmetric equilibrium with a single firm in each country, the results pertaining to a single firm are also applicable to the country's aggregate producer surplus. This consists of the discounted sum of instantaneous producer surplus over the infinite horizon, as given by the value functions, (18) and (21), in the Appendix.

We note that, in Region 1, at the steady state, we have $V^{A}\left(S_{1, \infty}^{A}\right)>V^{F T}\left(S_{1, \infty}^{F T}\right)=$

$\frac{(2 \delta-r+n r)^{2}(n-1)^{2} a^{2}}{4(r-2 \delta+n r)^{2}(n+1)^{2} b r}>0$. Moreover, for $n=2$ we can show analytically that for any $S \in$ $\left[S_{1}^{A}, S_{2}^{A}\right]$ we have $V^{A}(S)>V^{F T}(S)$. Thus, free trade results in a decrease in instantaneous producer surplus in the short-run and in the long-run, such that the impact of free trade on producer surplus when the transition dynamics is taken into account is to decrease aggregate producer surplus. Numerical simulations for $n>2$ yield the same conclusion.

For $n=2$ and $S \in\left[S_{1}^{A}, S_{2}^{A}\right]$,

$$
V^{A}(S)-V^{F T}(S)=u(\delta, r) S^{2}+v(\delta, r) S+x(\delta, r)
$$


where

$$
\begin{gathered}
u(\delta, r) \equiv-\frac{1}{288 b r \delta^{2}}\left(30 b^{2} r \delta^{3}-15 b^{2} r^{2} \delta^{2}\right) \\
v(\delta, r) \equiv-\frac{1}{288 b r \delta^{2}}\left(12 a b r^{2} \delta-24 a b r \delta^{2}\right) \\
x(\delta, r) \equiv-\frac{1}{288 b r \delta^{2}}\left(4 a^{2} r^{2}-8 a^{2} r \delta-8 a^{2} \delta^{2}\right)
\end{gathered}
$$

Note that

$$
\begin{gathered}
u(\delta, r)=r u\left(\frac{\delta}{r}, 1\right) \\
v(\delta, r)=v\left(\frac{\delta}{r}, 1\right) \\
x(\delta, r)=\frac{1}{r} l\left(\frac{\delta}{r}, 1\right)
\end{gathered}
$$

and therefore the sign of $u, v$, and $x$ depends on the ratio $\frac{\delta}{r}$ only, and that we can normalize $r$ to 1 for the rest of proof without loss of generality. This yields the following:

$$
\begin{gathered}
u(\delta, 1)=-\frac{15 b}{288}(2 \delta-1) \\
v(\delta, 1)=\frac{12 a}{288 \delta}(2 \delta-1) \\
x(\delta, 1)=\frac{4 a^{2}}{288 b \delta^{2}}\left(2 \delta+2 \delta^{2}-1\right)
\end{gathered}
$$

As noted earlier, from Assumption 1 we have $\delta>\frac{5}{2}$ for $n=2$ and, therefore, $u(\delta, 1)<0$, $v(\delta, 1)>0$ and $x(\delta, 1)>0$. Thus, $V^{A}(S)-V^{F T}(S)$ is a strictly concave function with a positive intercept at $S=0$. It is, therefore, straightforward to show that $V^{A}(S)-V^{F T}(S)>$ 0 for Region 1. We have thus proven that in Region $1, V^{A}(S)>V^{F T}(S)$ and therefore Free Trade results in a smaller aggregate producer surplus than Autarky. This result combined with the observation that in Region 3 we also have $V^{A}(S)>V^{F T}(S)$ allows us to conclude 
that Free Trade decreases producer surplus regardless of the initial stock level.

\subsection{Aggregate social welfare under Autarky and Free Trade}

Let $W_{i}^{A}$ denote the aggregate social welfare over time of country $i$ under Autarky, where $W_{i}^{A} \equiv C S_{i}^{A}+V_{i}^{A}$. Let $W_{i}^{F T}$ denote the aggregate social welfare of country $i$ under Free Trade, where $W_{i}^{F T} \equiv C S_{i}^{F T}+V_{i}^{F T}$.

Our results pertaining to consumer surplus and producer surplus imply that in Region 1 we have $W_{i}^{A}>W_{i}^{F T}$. This, combined with the observation that in Region 3 we have $W_{i}^{A}<$ $W_{i}^{F T}$, and using continuity of $W(S)$ allows us to conclude that there exists a threshold stock

$\hat{S}$ in Region 2 such that $W^{A}(\hat{S})=W^{F T}(\hat{S})$ and $W^{A}(S)<(>) W^{F T}(S)$ for $S>(<) \hat{S}$.

\section{Conclusion}

We examine the impact of opening up an economy to allow free trade in a common pool renewable resource such as fish, using a differential game framework. Our model consists of $n$ countries with one firm each. Each country also consumes the resource. Under free trade, the firms compete in quantities in a single integrated market using closed loop strategies.

Most static trade models predict an increase in world output due to freer trade, which is associated with higher consumer surplus. By incorporating the open access externalities associated with common pool resources within a dynamic framework, we show that the increase in output due to freer trade is temporary and ultimately leads to a lower steady state stock level than under autarky. This is in line with empirical observations which show that yields from oceans and fresh water fisheries have remained constant in recent years, with increasing trade in fish being accounted for by growing production from fish farms, raising concerns that peak production may have been reached in this industry. Moreover, we show that the increase in consumer surplus associated with the trade-induced increase in output is also temporary, and is reversed in transition to the lower post-trade steady state stock 
level. We contribute to the existing literature by determining the conditions under which consumers are worse off due to freer trade, once we aggregate their gains and losses over time. By capturing the transition dynamics, we are able to show that aggregate consumer surplus decreases due to freer trade as long as the stock does not exceed a certain threshold, in sharp contrast to most static trade models. Producer surplus always decreases with a move from Autarky to Free Trade. Together, the results on consumer and producer surplus imply that there exists a threshold in terms of the stock level below which aggregate social welfare over time is lower under Free Trade than under Autarky.

We note that in the presence of wide asymmetries across countries, trade in renewable resources may indeed be beneficial to consumers in some countries. Our results are, therefore, most relevant to cases where countries have similar access to the common pool resource. This scenario may apply to the global fish industry where countries indirectly share similar access to the oceans and fresh water fisheries through a few large fishing companies which behave strategically in the world market. In a broader context, our results may also apply to global environmental problems caused by accumulative pollutants such as greenhouse gases

or plastic waste accumulation. In these contexts, the global environmental quality may be interpreted to be the renewable resource with its stock declining in the stock of the pollutant, which has some natural rate of decay and increases in emission levels.

\section{Appendix}

\section{Proof of Proposition 1:}

The first order condition associated with (3) is given by:

$$
a-2 b \phi_{i}^{A}-V_{i}^{A \prime}(S)=0
$$

which implies the following:

$$
\phi_{i}^{A}=\frac{a-V_{i}^{A \prime}(S)}{2 b}
$$

For a symmetric equilibrium, we have the following: 


$$
r V^{A}(S)=\frac{a^{2}+V^{A \prime}(S)(4 b \delta S-2 a n)+(2 n-1) V^{A / 2}}{4 b}
$$

Applying the "undetermined coefficient technique" (see, e.g. Benchekroun, 2008, for further details), from (17), we obtain the following value function:

$$
V^{A}(S)= \begin{cases}0, & 0 \leq S<S_{1}^{A} \\ W^{A}(S), & \text { for } S_{1}^{A} \leq S \leq S_{2}^{A} \\ \frac{a^{2}}{4 b}, & \text { for } S>S_{2}^{A}\end{cases}
$$

where,

$$
\begin{aligned}
& W^{A}(S) \equiv \frac{\alpha^{A} S^{2}}{2}+\beta^{A} S+\mu^{A} \\
& \text { with } \\
& \alpha^{A} \equiv \frac{2 b(r-2 \delta)}{2 n-1} \\
& \beta^{A} \equiv \operatorname{an} \frac{-r+2 \delta}{(2 n-1) \delta} \\
& \mu^{A} \equiv \frac{\left(a-\beta^{A}\right)\left(a+\beta^{A}-2 \beta^{A} n\right)}{4 b r} .
\end{aligned}
$$

Differentiating (18) with respect to $S$, and substituting into (16) yields Proposition 1

\section{Proof of Proposition 2:}

The first order condition associated with (7) is given by:

$$
a+\frac{b\left(-n \phi^{F T *}-2 \phi_{i}^{F T}+\phi^{F T *}\right)}{n}-V_{i}^{F T^{\prime}}(S)=0
$$


Assuming symmetry, we have the following:

$$
\phi_{i}^{F T}=\frac{n\left(a-V_{i}^{F T^{\prime}}(S)\right)}{b(n+1)}
$$

For a symmetric equilibrium, we have the following:

$$
r V_{i}^{F T}(S)=\frac{a^{2} n+V_{i}^{F T \prime}(S)\left(b \delta(n+1)^{2} S-a\left(n^{3}+n\right)\right)+n^{3}\left(V_{i}^{F T^{\prime}}(S)\right)^{2}}{b(n+1)^{2}}
$$

Applying the undetermined coefficient technique, from (20), we obtain the following value function:

$$
V^{F T}(S)= \begin{cases}0, & \text { for } 0 \leq S<S_{1}^{F T} \\ W^{F T}(S), & \text { for } S_{1}^{F T} \leq S \leq S_{2}^{F T} \\ a^{2} \frac{n}{b(n+1)^{2}}, & \text { for } S>S_{2}^{F T}\end{cases}
$$

where

$$
\begin{aligned}
& W^{F T}(S) \equiv \frac{\alpha^{F T} S^{2}}{2}+\beta^{F T} S+\mu^{F T} \\
& \text { with } \\
& \alpha^{F T} \equiv-\frac{b(n+1)^{2}(2 \delta-r)}{2 n^{3}} \\
& \beta^{F T} \equiv \frac{a \alpha^{F T} n\left(n^{2}+1\right)}{b(n+1)^{2}(\delta-r)+2 \alpha^{F T} n^{3}} \\
& \mu^{F T} \equiv \frac{n\left(a^{2}-a \beta^{F T}\left(n^{2}+1\right)+\left(\beta^{F T}\right)^{2} n^{2}\right)}{b(n+1)^{2} r}
\end{aligned}
$$

Differentiating (21) with respect to $S$, and substituting into (19) yields Proposition 2

\section{Proof of Proposition 4:}


From (6) and (10), we have the following:

$$
\frac{S_{1, \infty}^{F T}}{S_{1, \infty}^{A}}=\frac{2\left(2 \delta-r\left(1+n^{2}\right)\right)}{(n+1)(2 \delta-r(1+n)))}
$$

Since

$$
\frac{\left(2 \delta-r\left(1+n^{2}\right)\right)}{(2 \delta-r(1+n)))}<1,
$$

and

$$
\frac{2}{(n+1)}<1 \text { for } n>2,
$$

it follows that $\frac{S_{1, \infty}^{F T}}{S_{1, \infty}^{A}}<1$.

From (6) and (12), we have the following:

$$
\frac{S_{3, \infty}^{F T}}{S_{2, \infty}^{A}}=\frac{2(n+1) b \delta S_{y}+2 n^{2}\left(a S_{y}-a\right)}{2(n+1) b \delta S_{y}+n(n+1)\left(a S_{y}-a\right)}<1
$$

\section{References}

Batabyal, A.A. and H. Beladi (2006) "A Stackelberg game model of trade in renewable resources with competitive sellers," Review of International Economics, 14(1), 136147.

Benchekroun, H. (2003) "Unilateral production restrictions in a dynamic duopoly," Journal of Economic Theory, 111(2), 214-239.

Benchekroun, H. (2008) "Comparative dynamics in a productive asset oligopoly," Journal of Economic Theory 138(1), 237-261.

Benchekroun, H. and G. Gaudet (2015) "On the effects of mergers on equilibrium out-comes in a common property renewable asset oligopoly," Journal of Economic Dynamics and Control, 52, 209-223. 
Benchekroun, H., and N.V. Long (2016) "Status concern and the exploitation of common pool renewable resources," Ecological Economics, 125, 70-82.

Brander, J.A. and M.S. Taylor (1997) "International trade and open-access renewable resources: the small open economy case," Canadian Journal of Economics, 30, 526-552.

Brander, J.A. and M.S. Taylor (1998) "Open access renewable resources: trade and trade policy in a two-country model," Journal of International Economics, 44(2), 181-209.

Bulte, E.H. and E.B. Barbier (2005) "Trade and renewable resources in a second best world: An overview," Environmental and Resource Economics, 30(4), 423-463.

Colombo, L. and P. Labrecciosa (2013a) "Oligopoly exploitation of a private property productive asset," Journal of Economic Dynamics and Control, 37(4), 838-853.

Colombo, L. and P. Labrecciosa (2013b) "On the convergence to the Cournot equilibrium in a productive asset oligopoly," Journal of Mathematical Economics, 49(6), 441-445.

Colombo, L. and P. Labrecciosa (2018) "Consumer surplus-enhancing cooperation in a natural resource oligopoly," Journal of Environmental Economics and Management, 92, 185-193.

Dockner, E. J., S. Jorgensen, N.V. Long and G. Sorger (2000) "Differential games in economics and management science," Cambridge University Press.

Fujiwara, K. (2008) "Duopoly can be more anti-competitive than monopoly," Economics Letters, 101(3), 217-219.

Fujiwara, K. and T. Shinozaki (2010) "The closed-loop effects of market integration in a dynamic duopoly," Australian Economic Papers, 49(1), 1-12.

Fujiwara, K. (2011) "Losses from competition in a dynamic game model of a renewable resource oligopoly," Resource and Energy Economics, 33(1), 1-11. 
Grilli, L. and M. Bisceglia (2017) "A Duopoly with Common Renewable Resource and Incentives," International Game Theory Review, 19(4).

Hannesson, R. (2000) "Renewable resources and the gains from trade," Canadian Journal of Economics, 33(1), 122-132.

Jinji, N. (2006) "International trade and terrestrial open-access renewable resources in a small open economy," Canadian Journal of Economics, 39(3), 790-808.

Jinji, N. (2007) "International trade and renewable resources under asymmetries of resource abundance and resource management," Environmental and Resource Economics, 37(4), 621-642.

Kossioris, G., M. Plexousakis, A. Xepapadeas and A. de Zeeuw (2011) "On the optimal taxation of common-pool resources," Journal of Economic Dynamics and Control, 35(11), 1868-1879.

Lambertini, L. and A. Mantovani (2014) "Feedback equilibria in a dynamic renewable resource oligopoly: Pre-emption, voracity and exhaustion," Journal of Economic Dynamics and Control, 47(C), 115-122.

Lambertini, L. and A. Mantovani (2016) "On the (in) stability of nonlinear feedback solutions in a dynamic duopoly with renewable resource exploitation," Economics Letters, $143,9-12$.

Munro, G.R. (1979) "The optimal management of transboundary renewable resources," Canadian Journal of Economics, 355-376.

Quaas, M.F. and M.T. Stöven (2014) "New trade in renewable resources and consumer preferences for diversity," No. 2014-08, Economics Working Papers, Christian-AlbrechtsUniversity of Kiel, Department of Economics. 
Vardar, B. and G. Zaccour (2018) "Exploitation of a Productive Asset in the Presence of Strategic Behavior and Pollution Externalities," G-2018-43, Cahiers du GERAD.

World Trade Report 2010: Trade in Natural Resources, World Trade Organization. 